\title{
Non-steroidal anti-inflammatory drugs are associated with emergency admission to hospital for colitis due to inflammatory bowel disease
}

\author{
J M M Evans, A D McMahon, F E Murray, D G McDevitt, T M MacDonald
}

\begin{abstract}
Background-To evaluate the relation between non-steroidal anti-inflammatory drugs (NSAIDs) and colitis due to inflammatory bowel disease.

Methods-A case-control study was conducted using a prospectively constructed, record linkage database containing hospital event and dispensed drug data (1989-93). The study population consisted of 319465 people resident in Tayside in January 1989, and still resident (or dead) in October 1994.

Results-Of the 785 patients admitted to hospital as emergencies with colitis between July 1989 and June 1993, 200 fulfilled the case criterion of colitis due to inflammatory bowel disease. A further 1198 persons were used as community controls. Odds ratios were calculated for three exposure periods (current, recent, and past exposure). The overall odds ratios (with $95 \%$ confidence intervals) for current and recent exposure to NSAIDs were $1.77(1.01$ to $3 \cdot 10)$ and $1.93(1.20$ to $3 \cdot 09)$ respectively. Current and recent exposure to NSAIDs was also associated for incident cases, with odds ratios of $2.96(1.32$ to 6.64$)$ and $2 \cdot 51(1 \cdot 13$ to $5 \cdot 55)$. There was a trend for recent exposure among non-incident cases.

Conclusion-The use of NSAIDs may be associated with an increased risk of emergency admission to hospital for colitis due to inflammatory bowel disease, particularly among patients with no previous history.

(Gut 1997; 40: 619-622)
\end{abstract}

Keywords: ulcerative colitis, Crohn's colitis, colitis, NSAIDs, case-control study.

Non-steroidal anti-inflammatory drugs (NSAIDs) are now widely recognised as a cause of serious upper gastrointestinal complications. ${ }^{12}$ However, the association between these agents and colitis has not been clearly elucidated. There have been case reports of de novo colitis associated with NSAID use and also of NSAIDs reactivating quiescent colitis. $^{3-7}$ A possible mechanism could be that NSAIDs inhibit prostaglandin synthesis, which is required for normal immune regulation and defence in the colon.

There have been no large scale epidemiological studies that have investigated the asso- ciation between colitis and NSAID use, probably because of the difficulties of mounting such studies without access to detailed and long term prescribing information. We conducted a study using an automated database at the Medicines Monitoring Unit (MEMO), University of Dundee. This database contains information about NSAIDs that have been prescribed and dispensed.

\section{Methods}

This study was carried out using a record linkage database that was designed for pharmacoepidemiological research. The database contains prospectively collected, patient specific data on all prescriptions for NSAIDs that were dispensed in the Tayside region since January 1989. Computerised diagnostic and demographic data on all Tayside hospital discharges since 1980 (Scottish Morbidity Record 1) are also available with diagnostic codes from the International Classification of Diseases, ninth revision (ICD-9) ${ }^{8}$ These data are patient specific and are indexed by a 10 digit number, the Community Health Index Number (CHNo), which all residents of Tayside are assigned when they register with a general practitioner. The CHNo allows the temporal linking of dispensed prescribing and hospitalised morbidity. The data collection methods for this database have been described in detail elsewhere. ${ }^{9-12}$

STUDY POPULATION

The study population consisted of 319465 patients who were alive, resident in Tayside and registered with a Tayside GP in January 1989 and were either still resident in October 1994, or had died in Tayside during this period. Complete records of dispensed NSAIDs exist for this population from January 1989 to December 1993.

\section{CASES}

All patients in the study population who were admitted to hospital as an emergency admission with an ICD-9 code for colitis between July 1989 and June 1993 were identified. To maximise the number of potential cases, a wide range of codes was used. These were $555 \cdot 1$ (Crohn's disease of the large intestine), $555 \cdot 2$ (Crohn's disease of the small intestine with large intestine), 555.9 (Crohn's disease of unspecified site), 556.0 and 556.9 (ulcerative 
colitis), and 558.9 (other non-infective colitis). The hospital medical records of patients with these codes were retrieved and checked where possible. They were defined as definite cases and included in the study if the medical records contained information judged to be supportive of a diagnosis of colitis due to inflammatory bowel disease. The validation was based on all the information available in the medical records, including results of biopsies, endoscopies, barium studies, operation records, history and clinical findings. Where possible, a diagnosis of Crohn's colitis or ulcerative colitis was made, according to the criteria of Lennard-Jones. ${ }^{13}$

The first admission to hospital with one of the specified diagnostic codes was taken as the index episode. A case was defined as an incident case if there was no previous history of lower gastrointestinal tract symptoms or other large bowel disorders noted in the medical records.

\section{CONTROLS}

Up to six community controls, matched for sex and age (within 30 days) were chosen from the study population for each case. The only patients in the study population who were excluded from being controls were potential subjects whose hospital case records could not be retrieved and checked. The index date for the control was the date of hospital admission of its matched case. A computing technicality required that all community controls were still alive in September 1992.

\section{STATISTICAL ANALYSES}

Data on exposure to dispensed NSAIDs were assembled for every case and control. To investigate the temporal nature of the association, the exposure variables were defined according to whether a prescription for an NSAID had been dispensed during any of three mutually exclusive exposure periods. A case or a control could be exposed in any one or any combination of these periods. They were (a) current exposure, within 45 days before the index date; $(b)$ recent exposure, between 45 and 180 days before the index date; and $(c)$ past exposure, at any time from January 1989 to more than 180 days before the index date. Unadjusted odds ratios (with 95\% confidence intervals) were calculated for each variable. Adjusted odds ratios were also calculated to assess whether any of the exposure variables had an independent effect. These analyses used conditional logistic regression.

The data were also analysed according to whether the case was incident or otherwise, and by diagnosis. In addition, because colitis is known to be associated with arthritis, for which NSAIDs are commonly prescribed, an analysis was carried out in which subjects who had previously been admitted to hospital (since 1980) with a diagnosis code for any musculoskeletal or connective tissue disease (ICD-9 codes 710-739) were excluded. Finally, because diarrhoea is a recognised complication of mefenamic acid, the number of patients exposed to mefenamic acid was checked to assess whether this might affect the results.

\section{Results}

CASES

Between July 1989 and June 1993, 785 patients in the study population were admitted to hospital as an emergency with one of the specified diagnostic codes. The medical records of 587 of these cases were available for checking, of which 200 were judged to fulfil the criterion of colitis due to inflammatory bowel disease and were included in the study. Most $(80 \%)$ of those that were excluded had an ICD-9 code of 558, which includes many nonspecific conditions such as radiation gastritis, allergic gastroenteritis and colitis, and noninfective gastroenteritis. In the remainder, a diagnosis of inflammatory bowel disease could not be confirmed. One hundred and six (53\%) of the cases were female and $94(47 \%)$ were male. The mean age at admission was 46 years (range 9-96). There were 96 (48\%) under the age of $45,62(31 \%)$ aged between 45 and 64 , and $42(21 \%)$ aged 65 or over. The medical records of 198 patients could not be located, therefore they were excluded from the study.

There were 113 cases of Crohn's colitis (mean age at admission 43) and 85 cases of ulcerative colitis (mean age at admission 50). Two cases could not be classified. Seventy three $(37 \%)$ of the cases were incident. Thirty six $(18 \%)$ had previously been admitted to hospital with a diagnosis of musculoskeletal or connective tissue disease. Table I shows the distribution of the cases. The patients with Crohn's colitis were slightly younger overall than the other patients. They were also less likely to be incident cases than cases of ulcerative colitis.

\section{CONTROLS}

There were 1198 suitable community controls, matched for age and sex, selected for the 200 cases.

STATISTICAL ANALYSES

Table II shows the odds ratios for the NSAID exposure variables for all cases. Current and recent NSAID exposure was significantly

TABLE I Diagnoses of cases in the study

\begin{tabular}{llllr}
\hline Type of case & $\begin{array}{l}\text { Crohn's } \\
\text { colitis }\end{array}$ & $\begin{array}{l}\text { Ulcerative } \\
\text { colitis }\end{array}$ & $\begin{array}{l}\text { Unspecified } \\
\text { diagnosis }\end{array}$ & Total \\
\hline All cases & $113(57)$ & $85(43)$ & 2 & 200 \\
$\quad$ No (\%) & 43 & 50 & & 46 \\
$\quad \begin{array}{l}\text { Mean age (years) } \\
\text { Incident }\end{array}$ & $23(32)$ & $49(67)$ & 1 & 73 \\
$\quad$ No (\%) & 40 & 49 & & 46 \\
$\quad \begin{array}{l}\text { Mean age (years) } \\
\text { Non-incident }\end{array}$ & 40 & & & \\
$\quad$ No (\%) & $90(71)$ & $36(28)$ & 1 & 127 \\
Mean age (years) & 44 & 51 & & 46 \\
\hline
\end{tabular}

*Includes two cases which could not be classified into Crohn's colitis or ulcerative colitis. 
TABLE II Unadjusted and adjusted exposure odds ratios for NSAIDs among all patients, and among patients with no prior history of musculoskeletal and joint disease

\begin{tabular}{|c|c|c|c|c|}
\hline $\begin{array}{l}\text { Type of } \\
\text { case }\end{array}$ & $\begin{array}{l}\text { No (\%) of } \\
\text { patients exposed }\end{array}$ & $\begin{array}{l}\text { No (\%) of } \\
\text { controls exposed }\end{array}$ & $\begin{array}{l}\text { Unadjusted odds } \\
\text { ratio }(95 \% \text { CI) }\end{array}$ & $\begin{array}{l}\text { Adjusted odds } \\
\text { ratio }(95 \% C I)\end{array}$ \\
\hline $\begin{array}{l}\text { All cases } \\
\text { Current } \\
\text { Recent } \\
\text { Past }\end{array}$ & $\begin{array}{l}18(9) \\
27(14) \\
50(25)\end{array}$ & $\begin{array}{c}65(5 \cdot 4) \\
93(7 \cdot 8) \\
278(23 \cdot 2)\end{array}$ & $\begin{array}{l}1.77(1.01 \text { to } 3.10) \\
1.93(1.20 \text { to } 3.09) \\
1.12(0.78 \text { to } 1.61)\end{array}$ & $\begin{array}{l}1.35(0.72 \text { to } 2.56) \\
1.76(1.02 \text { to } 3.03) \\
0.95(0.64 \text { to } 1.40)\end{array}$ \\
\hline $\begin{array}{l}\text { Cases with } \\
\text { Current } \\
\text { Recent } \\
\text { Past }\end{array}$ & $\begin{array}{l}\text { prior history of } \\
13(8) \\
20(12) \\
40(24)\end{array}$ & $\begin{array}{l}\text { usculoskeletal or } \\
53(5 \cdot 4) \\
72(7 \cdot 3) \\
224(22 \cdot 8)\end{array}$ & $\begin{array}{l}\text { onnective tissue diseas } \\
1.54(0.81 \text { to } 2 \cdot 93) \\
1.84(1.06 \text { to } 3 \cdot 18) \\
1 \cdot 10(0.74 \text { to } 1.66)\end{array}$ & $\begin{array}{l}1.18(0.57 \text { to } 2.43) \\
1.75(0.94 \text { to } 3.29) \\
0.97(0.63 \text { to } 1.49)\end{array}$ \\
\hline
\end{tabular}

TABLE III Unadjusted and adjusted exposure odds ratios for NSAIDs among patients, stratified by incidence and diagnosis

\begin{tabular}{|c|c|c|c|c|}
\hline $\begin{array}{l}\text { Type of } \\
\text { case }\end{array}$ & $\begin{array}{l}\text { No (\%) of } \\
\text { patients exposed }\end{array}$ & $\begin{array}{l}\text { No (\%) of } \\
\text { controls exposed }\end{array}$ & $\begin{array}{l}\text { Unadjusted odds } \\
\text { ratio }(95 \% C I)\end{array}$ & $\begin{array}{l}\text { Adjusted odds } \\
\text { ratio }(95 \% C I)\end{array}$ \\
\hline \multicolumn{5}{|c|}{ Incident cases } \\
\hline Current & $10(14)$ & $23(5 \cdot 3)$ & $2.96(1.32$ to 6.64$)$ & $2.39(0.91$ to 6.32$)$ \\
\hline Recent & $11(15)$ & $32(7 \cdot 3)$ & $2.51(1.13$ to 5.55$)$ & $1.89(0.71$ to 5.01$)$ \\
\hline Past & $17(23)$ & $109(25 \cdot 0)$ & $0.91(0.49$ to 1.68$)$ & $0.69(0.35$ to 1.35$)$ \\
\hline \multicolumn{5}{|c|}{ Non-incident cases } \\
\hline Current & $8(6)$ & $42(5 \cdot 5)$ & $1.16(0.52$ to 2.59$)$ & $0.85(0.35$ to 2.05$)$ \\
\hline Recent & $16(13)$ & $61(8 \cdot 0)$ & $1.68(0.93$ to 3.03$)$ & $1.67(0.86$ to 3.24$)$ \\
\hline Past & $33(26)$ & $169(22 \cdot 2)$ & $1.25(0.80$ to 1.97$)$ & $1.15(0.72$ to 1.86$)$ \\
\hline \multicolumn{5}{|c|}{ Crohn's colitis } \\
\hline Current & $9(8)$ & $41(6 \cdot 1)$ & $1.36(0.63$ to 2.92$)$ & $1.12(0.48$ to 2.59$)$ \\
\hline Recent & $15(13)$ & $60(8.9)$ & $1.62(0.87$ to 3.04$)$ & $1.59(0.79$ to 3.19$)$ \\
\hline Past & $27(24)$ & $152(22 \cdot 4)$ & $1.09(0.67$ to 1.78$)$ & $0.98(0.58$ to 1.64$)$ \\
\hline \multicolumn{5}{|c|}{ Ulcerative colitis } \\
\hline Current & $9(11)$ & $24(4 \cdot 7)$ & $2.54(1.09$ to 5.91$)$ & $1.72(0.62$ to 4.79$)$ \\
\hline Recent & $12(14)$ & $33(6 \cdot 5)$ & $2.45(1.19$ to 5.03$)$ & $1.96(0.81$ to 4.75$)$ \\
\hline Past & $23(27)$ & $124(24 \cdot 4)$ & $1.17(0.68$ to 2.03$)$ & $0.94(0.52$ to 1.71$)$ \\
\hline
\end{tabular}

associated with a near doubling of the risk of emergency admission to hospital for colitis due to inflammatory bowel disease. Recent use, after adjusting for the effects of current exposure, was independently associated with an increased risk of admission to hospital. When the 36 cases with a prior admission for musculoskeletal or connective tissue disease were excluded, recent exposure to NSAIDs was still associated with an increased risk of admission to hospital.

Table III presents the exposure odds ratios among the 73 cases with no prior history of lower gastrointestinal tract symptoms or large bowel disorders (incident cases) and cases who did have such a history (non-incident cases). Current and recent exposure to NSAIDs was associated with increased risks of incident colitis due to inflammatory bowel disease of $2.96(1.32$ to $6 \cdot 64)$ and $2 \cdot 51(1.13$ to $5 \cdot 55)$ respectively. Although there were no statistically significant associations evident among non-incident cases, the unadjusted odds ratio for recent exposure was 1.68 (0.93 to 3.03).

Table III shows also separate analyses for the cases of Crohn's disease and ulcerative colitis and their corresponding controls. The unadjusted odds ratios were higher for ulcerative colitis.

Only 13 cases were exposed to mefenamic acid at any time (three currently).

\section{Discussion}

In this case-control study, three exposure variables were investigated for NSAIDs. Current exposure was based on a 45 day period as a large proportion of NSAID prescriptions are given for one month, allowing 15 days for a pharmacological carry over effect. Recent exposure was between 45 days and 180 days before the index date. One hundred and eighty days is the maximum length of time for which complete prescribing records definitely exist for every case and control because exposure records began in January 1989 and patients were admitted to hospital from July 1989. Past exposure was exposure from January 1989 to 180 days before the index date, each set of cases and its corresponding controls therefore having different time periods for past exposure. The exposure variables were not independent, as a patient exposed in one time period could also be exposed in another. Conditional logistic regression was therefore used to determine whether any exposure period was independently more important, although our unadjusted results are the most informative and should be regarded as the main outcome measures.

Associations were found between current and recent NSAID use and emergency admission to hospital with colitis due to inflammatory bowel disease. There was an approximate doubling of the risk for both. In the adjusted analysis, only recent use was independently associated with an increased risk, probably because a high proportion of patients who were currently exposed were also recently exposed. It is an important finding that NSAID exposure (at some point during the previous six months) results in an increased risk of admission to hospital for colitis due to inflammatory bowel disease.

In analyses among subgroups of cases with and without a previous history of gastrointestinal symptoms, associations between current and recent NSAID exposure among incident cases were present. These risks were relatively high, with unadjusted odds ratios of between 2.5 and 3 , while for non-incident cases, they were lower and not statistically significant. Nevertheless, there is evidence of a trend for increased risk for recent exposure. Such an association with NSAID use among non-incident cases is possible as there has been some evidence that NSAID use reactivates quiescent colitis. ${ }^{5}$ Walt et al ${ }^{14}$ propose that this reactivation also occurs rapidly, although we found a trend for recent but not current exposure among these cases. This may be because NSAID treatment is withdrawn once reactivated colitis is recognised.

Separate analyses by diagnosis produced higher unadjusted odds ratios for ulcerative colitis. It is difficult to establish whether these results are due to a clinical difference between ulcerative colitis and Crohn's disease, or because a higher proportion of ulcerative colitis cases are incident. However, these subgroup analyses should all be interpreted with caution, ${ }^{15}$ and in this particular study the reduced sample sizes make interpretation less certain.

It is important to assess whether the associations evident for NSAIDs are causal. Exposure to mefenamic acid does not explain the results. NSAID use could be spuriously associated with colitis because colitis is associated 
with arthropathy for which NSAIDs are commonly prescribed (confounding by indication). There are three reasons why we rule out this explanation for the observed findings. Firstly, although there is eventual articular involvement in $6-25 \%$ of patients with colitis, it is rare for patients to have arthritic symptoms before intestinal symptoms. ${ }^{16}$ Secondly, when we excluded the 36 patients who had previously been admitted to hospital with musculoskeletal or connective tissue disease, among whom confounding by indication was most likely to be present, the association for recent exposure remained. Finally, confounding by indication would be stronger among non-incident cases. These were patients who had had colitis for longer and were therefore more likely to have developed arthritic symptoms. However, the associations were less strong in this subgroup of cases.

Selection of appropriate cases and controls is important. Our patients were all admitted to hospital as emergencies with a definite diagnosis of colitis due to inflammatory bowel disease. We checked that exclusion of cases for which medical records could not be found did not introduce selection bias. The average age of the cases was 47 , which is higher than the peak incidence of 20-40 years often reported, probably because the cases were not representative of all patients with colitis in the study population. However, we were primarily interested in the serious toxicity of drugs so we evaluated the risk for admission to hospital with colitis.

Our case-control study used community controls, because even though the patients were admitted to hospital, they came straight from the community as emergency cases. It is our experience that the use of hospital controls results in lower odds ratios than with community controls, because the exposure of patients in hospital to NSAIDs is not representative of that in the study population. ${ }^{11} 12$ The associations in this study might not have been evident had hospital controls been used. This possible error is perhaps more important than any bias resulting from unknown selection forces acting upon the chance of admission to hospital, the reason often cited for use of hospital controls. ${ }^{17}$ We therefore considered community controls to be the more appropriate choice.

The strengths and limitations of using the MEMO databases to conduct case-control studies have been discussed elsewhere. ${ }^{11} 12 \mathrm{We}$ do not consider the use of over the counter NSAIDs resulted in exposure misclassification, or that temporal exposure misclassification or selection bias were important sources of error.

This study used comprehensive exposure data for a well defined population with validated cases of colitis and community controls. Associations were found between the use of NSAIDs and emergency admission to hospital for colitis due to inflammatory bowel disease, which were consistent with information already known. Although not conclusive, this study does provide support for the hypothesis that NSAIDs are implicated in colitis due to inflammatory bowel disease. However, to elucidate further the nature of these associations, more studies should be carried out using the broader spectrum of cases of colitis encountered in clinical practice.

The Medicines Monitoring Unit is supported by the Medicine Control Agency.

1 Garcia-Rodriguez LA, Jick H. Risk of upper gastrointestina bleeding and perforation associated with individual nonsteroidal anti-inflammatory drugs. Lancet 1994; 343 769-72.

2 Langman MJS, Weil J, Wainwright $\mathrm{P}$, Lawson $\mathrm{DH}$ Rawlins MD, Logan RFA, et al. Risks of bleeding peptic ulcer associated with individual non-steroidal antiinflammatory drugs. Lancet 1994; 343: 1075-8.

3 Phillips MS, Fehilly B, Stewart S, Dronfield MW. Enteritis and colitis associated with mefenamic acid. BMF 1987; 287: 1626 .

4 Hall RI, Petty AH, Cobden I, Lendrum R. Enteritis and colitis associated with mefenamic acid. BMF 1983; 287: 1182 .

5 Kaufmann HJ, Taubin HL. Nonsteroidal anti-inflammatory drugs activate quiescent inflammatory bowel disease. $A n$ Intern Med 1987; 107: 513-6.

6 Gibson GR, Whitacre EB, Ricotti CA. Colitis induced by non-steroidal anti-inflammatory drugs. Arch Intern Med 1992; 152: 625-32.

7 Gleeson M, Ramsay D, Hutchinson S, Spencer D, Monteith G. Colitis associated with non-steroidal antiinflammatory drugs. Lancet 1994; 344: 1028.

8 International Classification of Diseases. Manual of the International Statistical Classification of Diseases, Injuries and Causes of Death. Vol 1. Geneva: World Health Organisation, 1977.

9 Evans JMM, McDevitt DG, MacDonald TM. The Tayside Medicines Monitoring Unit: a record-linkage system for pharmacovigilance. Pharmaceutical Medicine 1995; 9. $165-76$

10 MacDonald TM, McDevitt DG. The Tayside Medicines Monitoring Unit (MEMO). In: Strom BL, ed. Pharmaco epidemiology, 2nd edn. Chichester: Wiley, 1994: 245-55.

11 Evans JMM, McMahon AD, McGilchrist MM, White G McDevitt DG, MacDonald TM. Topical non-steroidal anti-inflammatory drugs and hospitalisation for upper gastrointestinal bleeding and perforation. BMF 1995; 311: $22-6$.

12 Evans JMM, McGregor E, McMahon AD, McGilchrist MM Jones MC, White G, et al. Non-steroidal anti-inflammaJones $M C$, White $\mathrm{G}$, et al. Non-steroidal anti-inflammatory drugs and hospitalisa

13 Lennard-Jones JE. Classification of inflammatory bowel disease. Scand f Gastroenterol 1989; 24: 2-6.

14 Walt RP, Hawkey CJ, Langman MJS. Colitis associated with non-steroidal anti-inflammatory drugs. $B M \mathcal{F} 1984 ; 288$ 238

15 Mills JL. Data torturing. N Engl f Med 1993; 329: 1196-9. 6 Lichtman SN, Sartor RB. Extraintestinal manifestations of inflammatory bowel disease: clinical aspects and natura history. In: Targan SR, Shanahan F, eds. Inflammatory bowel disease. From bench to bedside. Baltimore: Williams and Wilkins, 1994: 317-35.

17 Lasky T, Stolley PD. Selection of cases and controls. Epidemiol Rev 1994; 16: 6-17. 